\title{
Impacts of heating and surfactant treatments on the geotechnical properties of a cohesive soil
}

\section{A. R. Estabragh}

Associate Professor, Faculty of Soil and Water Engineering, University of Tehran, PO BOX 4411 Karaj 31587-77871, Iran

Tel: +982612241119

Fax: +982612226181

Email: raeesi@ut.ac.ir

\section{M.Babalar}

Postgraduate Student, Faculty of Soil and Water Engineering, University of Tehran, PO BOX 4411 Karaj 31587-77871, Iran

Tel: +982612241119

Fax: +982612226181

Email:

\section{A. A. Javadi}

Professor, Computational Geomechanics Group, Department of Engineering, University of Exeter, Devon, EX4 4QF, UK

Tel: +44 1392723640

Fax: +44 1392217965

Email : A.A.Javadi@Exeter.ac.uk

\section{E. Afsari}

Postgraduate Student, Faculty of Soil and Water Engineering, University of Tehran, PO BOX 4411 Karaj 31587-77871, Iran

Tel: +98 2612241119

Fax: +98 2612226181

Email: afsari.e@ut.ac.ir 


\title{
Impacts of heating and surfactant treatments on the geotechnical properties of a cohesive soil
}

\begin{abstract}
An experimental investigation was performed to assess the effect of heating and surfactant on treatment of a soil contaminated with gasoline. Contaminated soil samples were prepared by adding 5, 10 and $15 \%$ weight of gasoline to a cohesive soil. The contaminated soil samples were treated by applying heating at 50, 100 and $150^{\circ} \mathrm{C}$. In addition, treatment of the contaminated samples was done by using two different types of surfactant, namely SDS (Sodium Dodecyl Sulfate) and Tween 80. The physical and mechanical properties of the natural soil, contaminated soil and treated soil were determined through experimental tests including Atterberg limit, grain size distribution, compaction and unconfined compression tests. Comparison of the results showed that adding gasoline to soil changes its behavior and the amount of change was function of percent of gasoline. The results also indicated that heating can be used for treatment of the contaminated soil. Comparison of the results showed that using surfactant was more effective in treating the contaminated soil than thermal treatment and the properties of surfactant-treated soil were closer to the original condition. The results also showed that SDS surfactant was more effective in treating the contaminated soil than Tween 80 .

Key words: Cohesive soil, contaminated soil, gasoline, thermal treatment, surfactant,
\end{abstract} SDS, Tween 80 


\section{Introduction}

Organic chemicals are the foundation of numerous industries such as fuel refining, petrochemical complexes, pesticides and detergents. The improper use of organic chemicals and accidents are of increasing concern. Many of these compounds (e.g., fuels such as gasoline) have contaminated soil and water from improper use or storage. Contamination, both on land and in water, may also occur as a result of accidents during transport of petroleum products through pipelines, ships or trucks. Gasoline is considered as an environmental hazard when it leaks from underground storage tanks or petroleum storage facilities into environment. Gasoline and similar contaminants are often regarded as Light Non-Aqueous Phase Liquids (LNAPLs). A typical blend of gasoline is composed numerous hydrocarbons from which 13 chemicals are regulated as hazardous substances ([1]). The hazards of gasoline are mainly attributed to BTEX (Benzene, Toluene, Ethylbenzene and Xylene) components, particularly benzene content of it.

Understanding the chemical nature of organic contaminants and the response of the soil to them is important in selecting and assessing the method of remediation. Therefore, in order to successfully conduct a remediation program for a contaminant-affected site a thorough understanding of the chemical and physical properties of the contaminated compound is essential. The sensitivity of soil to contaminants depends upon the type of soil (such as particle size, mineral structure, bonding characteristics between particles and ion exchange capacity) and the nature of contaminants. Fang ([2]) defined a sensitivity index (ranging from 0 to 1 ) to different types of soil. Sensitivity of sand and gravel (0.01 to 0.1$)$ is much lower than clay particles $(0.6-0.9)$. When a soil is contaminated with chemical compounds its behavior can be quite different from that of the original soil. By 
contamination, chemical are adsorbed or trapped within the soil and soil pores. Based on the chemical compounds type of contaminant, soil type and location of contaminant within the soil mass the contaminated soil may gain completely different properties.

Contaminated land may require remediation with respect to either engineering or environmental considerations[3]. There are a number of techniques for remediation of contaminated land. These include physical (washing, flushing, thermal, vacuum extraction, solvent extraction), chemical (stabilization and solidification) and bioremediation techniques. However, the applicability and feasibility of different methods for remediation are dependent on many factors such as soil characteristics (soil type, degree of compaction and saturation), site geology, depth of contamination, extent of contaminant in lateral direction, topography, surface and ground water and the type and amount of contaminants. In addition, factors such as cost acceptance, on site application and short and long term effectiveness are important in selecting the method of remediation.

Thermal treatment is one of the most popular methods for remediation the soil contaminated with petroleum compounds. In this method the contaminants are desorbed from the soil when it is heated to $150-300{ }^{\circ} \mathrm{C}$ for a specific time.

Bioremediation is another in situ process for remediation or restoration of soils. It uses naturally occurring microorganisms to degrade harmful chemicals into less toxic or nontoxic compounds. This technique is particularly suited for remediation of soils contaminated with organic compounds such as petroleum and petroleum products. This method is time consuming and cannot be conducted in a geoenvironmental laboratory. 
Surfactants are surface active agents that are used to reduce interfacial tension and increase solubility of non-aqueous phase liquids. They have two distinct parts, namely hydrophobic and hydrophilic sections. The hydrophilic section of surfactant is polar and hence water soluble but the other section is non polar thus promoting aqueous solubilization of compounds of lower water solubility. Therefore, they usually act as a solvent and dissolve the oil. The positive and/or negative charge allows it to be water soluble under certain chemical conditions. Therefore, oil in soil can be removed by surfactant in water. The surfactant solution is spread from soil and by altering the chemical condition it can be precipitated with oil to decontaminated water ([4]). Surfactants are typically classified according to the nature of their head group as anionic, cationic and nonionic. Surfactants can be used to assist in the remediation of numerous types of hydrocarbon contaminants ([5]). The main features that should be considered when selecting surfactants include efficiency in removing the contaminant, cost, biodegradability, degradation products, toxicity to humans, animals and plants and ability to recycle ([6]). In addition, soil $\mathrm{pH}$, soil type, Cation Exchange Capacity (CEC), particles size, permeability and type of contaminant affect the removal efficiencies. Meegoda and Ratnaweera ([4]) used a surfactant that was a combination of anionic and nonionic surfactants for remediation a soil contaminated with motor oil. They reported that the surfactant is more effective in remediation of a soil contaminated with oil than the other techniques such as thermal method. Singh et al. ([3]) used SDS (Sodium Dodecyl Sulfate) surfactant for remediation of a soil contaminated with motor oil and found that acceptable level of remediation can be achieved by using this kind of surfactant. Lancelot et al. [7], Pamukcu and Wittle [8] and Kim and Lee [9] investigated 
the use of surfactants for remediation soil contaminated with petroleum hydrocarbons, polynuclear aromatic hydrocarbons and diesel oil respectively. They reported that surfactants are effective in remediation of contaminated soil. They concluded that using surfactant can be effective in remediation of soils contaminated with hydrocarbon compounds.

Review of the literature shows that remediation of soils contaminated with gasoline has not been investigated by physical techniques. In this work an attempt was made to remediate a soil contaminated with different percentages of gasoline through physical techniques in laboratory. The applied physical techniques were thermal technique and use of two different kinds of surfactant. Comparison is made between the behaviors of the the contaminated soils treated using the thermal technique or two different types of surfactant and the uncontaminated (virgin) soil.

\section{Materials}

Soil, gasoline and surfactant are the basic materials that were used in this work. The physical, mechanical and chemical properties of these materials are explained in this section.

\section{Soil}

The soil that was used in this testing program was a silty clay. The physical, mechanical and chemical properties of the soil are presented in Tables 1 and 2, indicating that the soil is essentially a clay with low plasticity (i.e. CL according to the Unified Soil Classification system (USCS)). The results of standard Proctor compaction test showed a maximum dry unit weight of $17.5 \mathrm{kN} / \mathrm{m}^{3}$ at an optimum water content of $17.3 \%$. XRD (X-ray diffraction) tests were conducted on the samples of the soil and the results are 
shown in Fig.1. As shown in Fig.1a the minerals of the soil include quartz, calcite, feldspar (Na, Ca) and feldspar (K). The results also show that the clay minerals of the soil are Illite, Chlorite and Montmorillonite (Fig.1b).

\section{Gasoline}

Gasoline was used as the contaminating compound. It was acquired from an Iranian Oil Company. The unit weight, boiling point and constant dielectric of the gasoline (based on the information obtained from the company) were $0.82-0.84 \mathrm{kN} / \mathrm{m}^{3}$ (at $25^{\circ} \mathrm{C}$ ), $385^{\circ} \mathrm{C}$ and 2 at $70^{\circ} \mathrm{F}$ respectively.

\section{Surfactant}

Two different types of ionic and nonionic surfactant, namely Tween 80 and SDS, were used for remediation of the soil samples contaminated with gasoline. The molecular weight of Tween 80 is $1309 \mathrm{~g}$ with chemical formula $\mathrm{C}_{64} \mathrm{H}_{124} \mathrm{O}_{26}$. The value of its HLB (hydrophilic lipophilic balance) is 13.4 ([10]). SDS (Sodium Dodecyl Sulfate) was another surfactant used in this work. The molecular weight of it was $288.5 \mathrm{~g}$ with chemical formula $\mathrm{NaC}_{12} \mathrm{H}_{25} \mathrm{SO}_{4}$.

\section{Preparation of samples}

The samples prepared included natural soil, soil contaminated with gasoline and remediated soil. Contaminated soil was prepared by adding 5, 10 and 15\% percent weight (to air dried soil) of gasoline. 5\% gasoline was selected as the minimum contaminant because the state of New Jersey classifies soil with oil concentration above $3 \%$ as hazardous waste. $6 \mathrm{~kg}$ air dried soil was selected and the desired amount of gasoline was weighted, then was sprayed on the soil and thoroughly mixed by hand for about 2 hours. The prepared mixture was kept inside a covered container for a week in order to come to 
equilibrium with the soil. Meegoda et al. ([11]) found that one week is sufficient for organic chemical to come to equilibrium with soil. Standard compaction tests were conducted on the natural soil, contaminated soil with different percents of gasoline and remediation soil using two physical methods. The samples for the main tests were prepared by static compaction according to the optimum water content and maximum dry unit weight that were obtained from standard compaction tests. In order to make the samples from natural, contaminated and remediated soil, the desired materials were weighted with an accuracy of $0.1 \mathrm{~g}$. Then water was added up to the relevant optimum water content and mixed in a container. The mixture was kept in a plastic sealed bag for 24 hours so that a uniform distribution of moisture was achieved. The samples were prepared in a cylindrical mould by static compaction in three layers. Each layer was compacted at the rate of $1.5 \mathrm{~mm} / \mathrm{min}$ until the maximum dry unit weight (according to the compaction test) was achieved. The length and diameter of the prepared samples were $100 \mathrm{~mm}$ and $50 \mathrm{~mm}$ respectively.

\section{Remediation}

The remediation of the contaminated soil was conducted by using thermal technique and surfactants as described below:

\section{Thermal remediation}

Contaminated soil with a specific percent of gasoline was kept inside a constant convection oven at 50,100 , and $150^{\circ} \mathrm{C}$ for about 48 hours to desorb the contaminating compound. During this time the soil was mixed regularly at intervals of 4 hours for uniform distribution of the thermal effect. The remediated soil then was cooled in air and the desired tests were performed on the samples of the soil. Selection of the temperatures 
of 50,100 and $150^{\circ} \mathrm{C}$ was based on the results that were reported by [12]. They showed that there was no change in the geotechnical behavior of soil on heating if the soil is not heated beyond $200{ }^{\circ} \mathrm{C}$. Therefore, it was decided to keep the contaminated soil samples in a convection oven at temperature below $200{ }^{\circ} \mathrm{C}$.

\section{Surfactant remediation}

Tween 80 and SDS were used for remediation of the contaminated soil. The amount of used Tween 80 was $25 \%$ weight of contaminating compound and selection the SDS amount was based on $50 \%$ weight of contaminating matter as used by [3] and [4]. The specific amount of surfactant was added to water; so, by adding this mixture to the soil the moisture of the soil exceeded the liquid limit. As the solution of surfactant was added to the soil it was mixed by hand regularly. The mixing was done for about two hours and after that the soil was allowed to settle. The duration of settlement of the soil particles was about 3-4 days. After that the excess liquid above the soil was drained off, the soil was then air dried and the desired samples were prepared from it for the experimental tests.

\section{Test program}

Atterberg limits, grain size distribution, compaction and unconfined compression tests were performed on samples of natural, contaminated and remediated soil according to the ASTM standard. For unconfined compression test the samples were loaded in a compression loading frame at an axial displacement rate of $1 \mathrm{~mm} / \mathrm{min}$. The applied load was recorded continually and the tests were continued until failure of sample was achieved. Scanning electron microscopy (SEM) tests were performed on the samples to observe the microstructure of the samples in natural and contaminated conditions. The 
samples with dimensions of $1 \mathrm{~cm}^{*} 1 \mathrm{~cm}^{*} 1 \mathrm{~cm}$ were prepared from natural and contaminated soil and scanned under SEM similar to the method that was used by [13] and [14].

\section{Results}

The values of Atterberg limits (LL, PL and PI) for the contaminated soil (with 5, 10 and $15 \%$ gasoline) before and after remediation using thermal treatment and surfactants are shown in Table.3. As shown in this table the liquid limit (LL) for natural soil was $40 \%$ but by adding 5, 10 and $15 \%$ gasoline it changed to $50 \%, 56 \%$ and $37 \%$. This trend can also be seen for the variation of plasticity index (PI) in this table. For the contaminated soil (with 5\% gasoline), after remediation the values of LL and PI decreased in comparison with the natural soil. On the other hand by increasing the temperature these values were decreased. For the soil contaminated with $10 \%$ gasoline, after remediation the values of LL and PL decreased more or less by the same amount as the remediated contaminated soil with 5\% gasoline. The values of LL and PL for remediation of soil by SDS surfactant show that the value of LL is nearly the same as natural soil but a slight reduction is seen in PI compared to the natural soil. The results for the soils treated with Tween 80 indicate that LL and PI are slightly less than natural soil.

The grain size distribution curves for the natural soil, contaminated soil with 5\%, 10 and $15 \%$ gasoline and the remediated soils by thermal and surfactant techniques are shown in Figs.2a, b and c respectively. As shown in these figures the percent of sand, silt and clay for natural soil are $15.28 \%, 56.32 \%$ and $25.4 \%$. These values for soil contaminated with $5 \%$ gasoline are changed to $16.63,62.37$ and $21 \%$ and for contaminated soil with $10 \%$ gasoline they are 22, 72 and $6 \%$. These figures show that by using thermal technique the 
percent of clay is decreased and the percent of sand and particularly silt is increased by increasing temperature. The results of grain size distribution for the soils remediated by SDS and Tween 80 (Figs.2a, $\mathrm{b}$ and c) show that the percent of clay is reduced but the percents of silt and sand are increased. Comparing the results of the two surfactants shows that the effect of Tween 80 in reduction of the percent of clay is more than SDS. Compaction curves for the contaminated soil with 5, 10 and 15\% gasoline before and after remediation by the two methods are shown Figs.3a, b and c. The results show that after thermal treatment, the maximum dry unit weight increases and the optimum water content decreases. For the contaminated soil with gasoline a reduction in maximum dry unit weight is observed compared with natural soil. The effect of SDS and Tween 80 on remediation soil is a reduction in maximum dry unit weight and optimum water content.

Fig.4 presents the stress-strain curves for natural soil, contaminated soil with 5, 10 and $15 \%$ gasoline and soil sample after remediation by heating and different surfactants. The results show that final strength of natural soil is $191 \mathrm{kPa}$ at strain of 6.2 . This value of strength for soil contaminated with 5, 10 and 15\% gasoline to 164.8, 112 and 51.8 (Figs. $4 \mathrm{a}, \mathrm{b}$ and c) respectively. It is resulted that adding gasoline to soil cause reduction in strength and that this is a function of percentage of gasoline used. Fig.4a shows the stress-strain curves for contaminated samples with 5\% gasoline after remediation by heating at temperature of 50,100 and $150^{\circ} \mathrm{C}$ and using surfactant. This figure demonstrates that the final strength of contaminated soil with $5 \%$ gasoline i.e. $164.8 \mathrm{kPa}$ was changed to 171,180 and $181 \mathrm{kPa}$ by remediation at temperatures of 50,100 and $150^{\circ}$ C. It is also observed that the value of strength ( $164.8 \mathrm{kPa})$ for contaminated soil with 5\% gasoline is changed to 219 and $193 \mathrm{kPa}$ after remediation with surfactans SDS and Tween 
80 respectively. A similar trend of stress-strain curves is seen in Fig, $4 \mathrm{~b}$ and $\mathrm{c}$ for soil contaminated with 10 and $15 \%$ gasoline and after remediation by heating and surfactant. For examples, it is seen that the final strength of soil contaminated with 10 and $15 \%$ gasoline (Fig.4b and c) are 111.2 and $51.7 \mathrm{kPa}$ respectively. These strength values are changed to $125.5,130,150 \mathrm{kPa}$ and $99.1,124$ and $139.8 \mathrm{kPa}$ due to remediation by heating at temperatures of 50,100 and $150^{\circ} \mathrm{C}$. Remediation by SDS and Tween 80 changed the strength of contaminated soil with 10 and $15 \%$ gasoline (111.2 and $51.7 \mathrm{kPa})$ to $190,120,180$ and $159 \mathrm{kPa}$ respectively

Fig. 5 shows the typical micrograph for the natural soil and soil contaminated with $15 \%$ gasoline. The flocculated structure is seen for the natural soil (Fig.5a). The micrograph for soil contaminated with $10 \%$ gasoline (Fig.5b) also shows the flocculated structure of soil. It is resulted from comparing the Figs.5a and $\mathrm{b}$ that adding gasoline cause increase in the degree of flocculated structure of soil sample. So, in this condition the more particles are pasted to each other and the pore between them is increased.

\section{Discussion}

The surface charges on clay particles are negative. These negative surface charges attract cations and the positively charged side of water molecules from surrounding water. Consequently, a thin film or layer of water (called adsorbed water) is bonded to the mineral surfaces. The thin layer of water is known as the diffuse double layer (DDL). The thickness of this layer is dependent on a number of factors such as dielectric constant, absolute temperature, etc. The physicochemical factors that contribute to the formation of clay structure are clay type and amount, ion type, valence and concentration in the pore fluid, dielectric constant, $\mathrm{pH}$, temperature of the pore fluid and amount of anion 
adsorption. Since all of the above factors were kept constant except the dielectric constant of pore fluid, therefore, it would be the only parameter that would contribute to the formation of different structures of soil. The dielectric constant of gasoline is nearly 2. It causes a flocculated structure in soil in which the particles paste to each other and form coarse particles in soil mass as shown in Fig.5. When organic chemical compounds come in contact with soil, the nature of the chemically reactive groups in the organic molecules, their shape, size, configuration, polarity, polarizability, and water solubility are important factors in determining the adsorption of these chemicals by the soil solids. These chemically reactive groups, which are also known as functional groups, populate both the surfaces of pollutants and soil solids. The chemical properties of the functional groups of the organic chemicals will influence the surface acidity of the soil particles. This is important in the adsorption of ionizable organic molecules by the soil solids (clays). The mechanisms of interaction between organic chemicals and soil fractions include (1) London-van der Waals forces, (2) hydrophobic bonding, (3) charge transfer, (4) ligand and ion exchange, and (5) chemisorption. Sorption of organic chemicals is enhanced when there is no hydration layer (of water) on the surfaces of soil particles ([15]). Therefore, the interaction mechanisms are influenced by the type of clay minerals and type of oil and presence of water. Yong ([15]) showed that there are no electronwithdrawing such as $\mathrm{C}=\mathrm{O}$ or $\mathrm{C}=\mathrm{N}$ associated with the molecules in the chemical structure of petroleum hydrocarbons such as polycyclic aromatic hydrocarbons (PAHs). Accordingly, the molecules of PHC would be weakly adsorbed (mainly by Van der Waals adsorption) by the soil functional groups, and do not involve any strong ionic interaction with various soil fractions. Weakly polar to non-polar compounds such as 
petroleum hydrocarbons (PHCs) develop different reactions and bonding relationships with the surface of soil fractions. Weakly polar compounds are more readily adsorbed onto soil surfaces in contrast to non-polar compounds. Yong and Rao ([16]) indicated that the adsorption of non-polar compounds onto soil surfaces is dominated by weak bonding (Van der Waals attraction) and is generally restricted to the external soil surfaces, primarily because of their low dielectric constant (less than 3). Contamination of the soil with gasoline causes these chemical compounds to penetrate between the layers of clay minerals, a process that is called intercalation ([17]). Intercalated guest molecules can be displaced by other suitable molecules.

The results of the LL tests for contaminated soil do not show this assumption, so the increase in the values of LL is observed. These results are consistent with the results that were reported by Khosravi et al. ([18]) who found from experimental tests that the values of LL and PI are increased with increasing the percent of gasoline beyond 12\%. Meegoda and Ratnaweera ([19]) indicated that the viscosity influences the liquid limit. Increase in the value of viscosity causes higher resistance or drag forces to impede rigid body motion and hence causes a higher liquid limit.

The results of grain size distribution curves (Figs.2a, b and c) of contaminated soil with 5 10 and $15 \%$ gasoline show that the percent of clay is reduced but the percent of sand and silt is increased. Comparing the results of soil contaminated with 5 and $10 \%$ gasoline indicates that this trend is more obvious for soil contaminated with $10 \%$ gasoline. It can be said that the gasoline causes reduction in the thickness of DDL because of low dielectric constant and hence a flocculated structure is formed. In the flocculated structure due to attractive forces, the fine particles paste to each other and form coarse 
particles. When the percent of gasoline is increased the degree of flocculation is increased so, more particles paste to each other and form coarser particles in comparison with the soil contaminated with $5 \%$ gasoline. The remediated samples with thermal treatment (Figs.2a and b) also show reduction in percent of clay and increase in the percent of sand and silt. It can be said that temperature can paste the particle to each other and form coarse particles. Zhang et al. ([20]) and Estabragh et al. ([21]-[22]) found from cyclic wetting and drying tests on clay soil that the potential of swelling is decreased by increasing the cycles of wetting and drying. They explained that during drying, heating of the sample causes pasting of the particles to each other and forming coarse particle in soil mass. Comparison of the results for remediation of the contaminated soil with 5, 10 and $15 \%$ gasoline at constant temperature shows that the amount of reduction in percent of clay for remediation of a soil contaminated with $10 \%$ gasoline is more than $5 \%$. This may be due to the excess of gasoline between particles in case of $10 \%$. The residual gasoline for soil contaminated with $10 \%$ gasoline after treatment at temperatures of 50, 100 and $150^{\circ} \mathrm{C}$ was measured using the GC (Gas Chromatography) apparatus. The result showed that the initial adsorbed gasoline was $8 \%$ but the residual amount of gasoline become 4, 3 and $1.5 \%$ after treatment at temperatures of 50,100 and $150^{\circ} \mathrm{C}$ respectively. The effects of SDS and Tween 80 for two conditions of remediation are shown in Figs.2a, b and c. These two surfactants cause a reduction in percent of clay and increase in percent of sand but this trend of variation is more obvious for remediation of soil contaminated with $10 \%$ gasoline. Comparing the results of SDS and Tween 80 shows that Tween 80 is more effective in reducing the percent of clay in comparison with SDS. It 
may be that during remediation some salts are formed and precipitate between particles and cause pasting to each other and forming coarse particles.

It is resulted from Figs.3a, b and $\mathrm{c}$ that samples remediated using the thermal technique show a small increase in maximum dry unit weight and reduction in optimum water content. This can be due to the formation of coarse particles by heating the soil. The samples that were treated with SDS and Tween 80 show a small reduction in maximum dry unit weight and a considerable reduction in optimum water content. As it was explained above, the precipitated salts between and around the particles decrease the potential for adsorbing water and reduce optimum water content. Comparing the results of contaminated soil with 5,10 and $15 \%$ gasoline shows that the maximum dry unit weight of them is nearly the same but the optimum water content of soil sample with $10 \%$ gasoline is considerably less than the sample contaminated with 5\% gasoline. In the case of soil contaminated with $10 \%$ gasoline a greater portion of the void space is occupied with gasoline than soil contaminated with $5 \%$ gasoline. Therefore, generally the water content (and hence the optimum water content) of the soil contaminated with $10 \%$ gasoline is lower.

It is seen from Figs. 4a, b and c that the final strength of natural soil is $191 \mathrm{kPa}$ but it is changed to $164.8,111.2$ and $51.8 \mathrm{kPa}$ when contaminated with 5, 10 and 155 gasoline. The values of E (Young Modulus) were calculated from the slope of the initial linear part of the stress-strain curves for the natural soil and soil samples contaminated with 5, 10 and $15 \%$ gasoline. The value of $\mathrm{E}$ for the natural soil was $6344 \mathrm{kPa}$ and for soil contaminated with 5, 10 and 15\% gasoline it was calculated as 4441, 3806 and $1268 \mathrm{kPa}$ respectively. Our findings show that adding gasoline to soil cause reduction in the 
stiffness of soil that this is a function of the percentage of gasoline contamination. Therefore, we have demonstrated that not only the strength of contaminated soil s decreased, but also the value of $\mathrm{E}$ is decreased in comparison with natural soil. These results are not in agreement with the theory of DDL. The reduction in dielectric constant would cause a flocculated structure in soil and the strength of the soil would increase in comparison with the natural soil (see Fig.5). This is because the dielectric constant of gasoline is nearly 2 that is much less than water. These findings are consistent with the results that were presented by Ratnaweera and Meegoda ([23]) who concluded (from experiments on clay samples mixed with different percentages of glycerol and propanol) that adding glycerol or propanol to the soil causes reduction in final strength. It can be said that the viscosity of pore liquid is important in facilitating displacement of particles. The viscosity of gasoline is more than water. This increases the rate of displacement of particles to each other and leads to decrease in the final strength of contaminated soil samples ([23]). The results show that after treatment of the samples, the final strength is increased in comparison with the contaminated soil and this increase at constant percent of gasoline is dependent on the applied temperature. It is resulted that the stress-strain curve is evoluted by increasing the temperature at constant percent of gasoline. The values of strain that the soil reached to the maximum final strength are reduced in comparing with contaminated soil and with increasing the temperature. For example the final strain of contaminated soil with $5 \%$ gasoline is occurred at strain of $7.6 \%$, but after remediation by heating this value of strain is changed to $7.42,7.25$ and 5.35 for temperatures of 50,100 and $150^{\circ} \mathrm{C}$ respectively. We can conclude that the ductility behavior of the sample is reduced by using heating method. The values of $\mathrm{E}$ were 
calculated for each temperature that was used for rememdiation of a soil contaminated at a specific percentage of gasoline. The results showed that the value is increased with increasing temperature. For example the E value at temperatures of 50,100 and $150^{\circ} \mathrm{C}$ for remediation a soil contaminated with $10 \%$ gasoline are 9139,11170 and $16250 \mathrm{kPa}$ respectively. A higher temperature causes more increase in the final strength. It can be explained that when the temperature is increased more gasoline is evaporated from between the particles and the viscosity between the particles is decreased which in turn leads to increase in the strength. Comparing the results for two different percentages of gasoline at constant temperature indicates that some gasoline can evaporate and when there is a higher percent of gasoline, after heating more gasoline is remained and causes reduction in the strength of sample. The final strength of samples after treatment with SDS and Tween 80 for is different. For the samples with 5\% gasoline, after remediation, the final of strength for both surfactants reach nearly to the final strength of natural soil but for samples that were contaminated with $10 \%$ gasoline the final strength is lower. The reason could be that the amount of surfactant that was used for 5\% and $10 \%$ contaminated soils was not the same.

This study shows that contaminated soil with gasoline produces greater changes in the behavior of the soil and the changes are a function of concentration of gasoline. The greater the concentration of gasoline, the greater is the change in the behavior of soil. The techniques of using heating and surfactants cause remediation of contaminated soil but it seems that surfactant is more effective than thermal treatment. However, more experimental evidence is needed to confirm this.

\section{Conclusion}


In this experimental work a cohesive soil was contaminated with 5,10 and $15 \%$ of gasoline. The experimental tests showed that the properties of contaminated soil are different from natural soil and the change in the properties is function of percent of gasoline. The contaminated soil was decontaminated by thermal treatment and also using two surfactants. The results showed that the method of thermal treatment cannot fully treat the contaminated soil to its original condition, particularly when the percent of gasoline is high. The results also showed that surfactant is more effective than heating in decontaminating the soil and can treat the soil nearly to its original condition. 


\section{References}

[1] Cheremisinoff P.N. A guide to Underground Storage Tanks: Evalution, Site assessment and Remediation. Prentice Hall, Englewood Cliffs, N.J. 1992.

[2] Fang H.Y. Introduction to Environmental Geotechnology, CRC Press, Boca Raton. Fla. 1997.

[3] Singh S.K, Srivastava R.K, John S. Studies on soil contamination due to used motor oil and its remediation. Can Geotech J 2009: 46: 1077-83.

[4] Meegoda N.J, Ratnaweera P. Treatment of oil-contaminated soils for identification and classification. Geotech Test J 1995: 18: 41-9.

[5] Mulligan C.N, Yong R.N, Gibbs B.F. Surfactant-enhannced remediation of contaminated soil: a review. Eng Geol 2001: 60: 371-80.

[6] Kimball S.L. Surfactant-enhanced soil flushing: an overview of an in situ remedial technology for soils contaminated with hydrophobic hydrocarbons. In: Proceeding Kostecki, P.T., Calabrese, E.J., Bonazountas, M. (Eds), Hydrocarbon contaminated soils, Vol.II, Lewis publishers, Boca Raton 1992.

[7] Lancelot F, Londiche H, De Marsily G. Experimental results on the influence of electric fields on the migration of oil, ionic species and water in porous media. $\mathbf{J}$ Petrol Sci Eng 1990: 4: 67-74.

[8] Pamukcu S, Wittle J.K. Electrokinetically enhanced in situ soil decontamination. Remediation of hazardous waste contaminated soils, 1994:245-98.

[9] Kim J, Lee K. Effects of electric field directions on surfactant enhanced electrokinetic remediation of diesel-contaminated sand column. J Environ Sci Health 1999:A34: 863-77. 
[10] Kim I.S, Park J.S, Kim K.W. Enhanced biodegradation of polycyclic aromatic hydrocarbons using nonionic surfactants in soil slurry. Appl Geochem 2001:16: 1419-28.

[11] Meegoda N.J, Rajapakse R.A, Gunesekara S.D, Chang K.G, Hyjack R.J.R, Cobo A.P. The influence of chemical contaminants on permeability and effective porosity of clays. CES-8708834 final report to the National Science Foundation,New Jersey, USA, 1990: 1-211.

[12] Wang M.C, Benway J.M, Arayssi A.M. The effect of heating on engineering Properties of Clays. Physico-Chemical Aspects of soil and Related materials, ASTM STP 1095, K.B. Hoddinott and r.O. Lamb, Eds., 1990:139-158.

[13] Tremblay H, Duchesne J, Locat J, Leroueil S. Influence of the nature of organic compounds on fire soil stabilization with cement. Can Geotech J 2002:39:535-46.

[14] Estabragh A.R, Khatibi M, Javadi A.A. Effect of cement on treatment of a clay soil contaminated with glycerol. J Mater Civil Eng, ASCE 2016:28:4015157.

[15] Yong R.N. Geoenvironmental Engineering, Contaminated soils Pollutant fate and Mitigation, CRC Press 2001.

[16] Yong R.N, Rao S.M. Mechanistic evaluation of mitigation of petroleum hydrocarbon contamination by soil medium. Can Geotech J 1991:28: 84-91.

[17] Lagaly G, Ogawa M, Dekany I. Clay mineral organic interaction, Handbook of clay science. , Bergaya F, Theng BKG, Lagaly G (eds.) 2006: 309-77

[18] Khosravi E, Ghasemzadeh H, Sabour M.R, Yazdani H. Geotechnical properties of gas oil-contaminated kaolinite. Eng Geol 2013: 166:11-6 
[19] Meegoda N.J, Ratnaweera P. Compressibility of contaminated fine-grained soils. Geotech Test J 1994: 17: 101-12.

[20] Zhang R, Yang H, Zheng J. The effect of vertical pressure on the deformation and strength of expansive soil during cyclic wetting and drying. In: Proceedings of the $4^{\text {th }}$ International Conference on Unsaturated soil. Arizona, USA $2006: 894-$ 905.

[21] Estabragh A.R, Moghadas M, Javadi A.A. Effect of different types of wetting fluids on the behaviour of expansive soil during wetting and drying. Soils Found 2013: 53: 621-31.

[22] Estabragh A.R, Parsaei B, Javadi A.A. Laboratory investigation of the effect of cyclic wetting and drying on the behaviour of an expansive soil. Soils Found 2015: 55:304-14.

[23] Ratnaweera P, Meegoda J.N. Shear strength and stress-strain behaviour of contaminated soils. Geotech Test J 2005: 24: 1-8. 
Table 1. Physical and mechanical properties of the soil

\begin{tabular}{|c|c|}
\hline Soil properties & Values \\
\hline Specific gravity & 2.67 \\
\hline \multicolumn{2}{|l|}{ Consistency limits } \\
\hline Liquid limit (LL) & $40 \%$ \\
\hline Plastic limit (PL) & $20 \%$ \\
\hline Plastic index (PI) & $20 \%$ \\
\hline Shrinkage limit (SL) & $13 \%$ \\
\hline USCS classification & CL \\
\hline \multicolumn{2}{|l|}{ Compaction study } \\
\hline Optimum water content & $17.3 \%$ \\
\hline Maximum dry density & $17.5 \mathrm{KN} / \mathrm{m}^{3}$ \\
\hline \multicolumn{2}{|l|}{ Grain size analysis } \\
\hline Sand & $15.28 \%$ \\
\hline Silt & $59.32 \%$ \\
\hline Clay & $25.4 \%$ \\
\hline
\end{tabular}


Table. 2 Chemical composition of soil

\begin{tabular}{|l|c|l|c|}
\hline $\begin{array}{l}\text { Chemical } \\
\text { component }\end{array}$ & Amount & $\begin{array}{l}\text { Chemical } \\
\text { component }\end{array}$ & Amount \\
\hline $\mathrm{pH}$ & 8.4 & $\mathrm{Mg}^{2+}($ meq/L) & 15.2 \\
\hline $\mathrm{EC}^{*}(\mathrm{dS} / \mathrm{m})$ & 6.42 & $\mathrm{Cl}^{-}($meq/L) & 32.8 \\
\hline $\mathrm{K}^{+}(\mathrm{meq} / \mathrm{L})$ & 3.4 & $\mathrm{HCO}^{-}(\mathrm{meq} / \mathrm{L})$ & 3.1 \\
\hline $\mathrm{Ca}^{2+}($ meq/L) & 17.9 & $\mathrm{SO}_{4}^{2-}($ meq/L) & 32.5 \\
\hline
\end{tabular}

Table 3 Atterberg limits for natural soil, contaminated soil with different percent of gasoline and treated soil from gasoline

\begin{tabular}{|c|c|c|c|c|c|}
\hline Material & \multicolumn{2}{|c|}{ Method of treatment } & $\begin{array}{l}\text { LL } \\
(\%)\end{array}$ & $\begin{array}{l}\text { PL } \\
(\%)\end{array}$ & $\begin{array}{l}\text { PI } \\
(\%)\end{array}$ \\
\hline $\begin{array}{l}\text { Natural } \\
\text { soil }\end{array}$ & \multicolumn{2}{|c|}{-} & 40 & 20 & 20 \\
\hline $\begin{array}{l}\text { Soil+5\% } \\
\text { gasoline }\end{array}$ & \multicolumn{2}{|c|}{ - } & 50 & 22 & 28 \\
\hline \multirow{5}{*}{$\begin{array}{l}\text { Treatment } \\
\text { soil+5\% } \\
\text { gasoline }\end{array}$} & \multirow{3}{*}{$\begin{array}{l}\text { Thermal } \\
\text { technique }\end{array}$} & $\mathrm{T}=50$ & 37 & 25 & 12 \\
\hline & & $\mathrm{T}=100$ & 33 & 25 & 8 \\
\hline & & $\mathrm{T}=150$ & 31 & 25 & 6 \\
\hline & \multirow{2}{*}{ Surfactant } & SDS & 41 & 27 & 14 \\
\hline & & Tween 80 & 34 & 22 & 12 \\
\hline $\begin{array}{c}\text { Soil+10\% } \\
\text { gasoline }\end{array}$ & \multicolumn{2}{|r|}{ 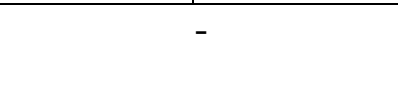 } & 56 & 30 & 26 \\
\hline \multirow{5}{*}{$\begin{array}{l}\text { Treatment } \\
\text { soil+10\% } \\
\text { gasoline }\end{array}$} & \multirow{3}{*}{$\begin{array}{l}\text { Thermal } \\
\text { technique }\end{array}$} & $\mathrm{T}=50$ & 42 & 22 & 20 \\
\hline & & $\mathrm{T}=100$ & 39 & 21 & 18 \\
\hline & & $\mathrm{T}=150$ & 37 & 20 & 17 \\
\hline & \multirow{2}{*}{ Surfactant } & SDS & 40 & 22 & 18 \\
\hline & & Tween 80 & 38 & 21 & 17 \\
\hline $\begin{array}{c}\text { Soil+15\% } \\
\text { gasoline }\end{array}$ & & & 37 & 25 & 12 \\
\hline \multirow{5}{*}{$\begin{array}{c}\text { Treatment } \\
\text { soil+15\% } \\
\text { gasoline }\end{array}$} & \multirow{3}{*}{$\begin{array}{l}\text { Thermal } \\
\text { technique }\end{array}$} & $\mathrm{T}=50$ & 50 & 36 & 14 \\
\hline & & $\mathrm{T}=100$ & 52 & 39 & 13 \\
\hline & & $\mathrm{T}=150$ & 53 & 40 & 13 \\
\hline & \multirow{2}{*}{ Surfactant } & SDS & 23 & 19 & 4 \\
\hline & & Tween 80 & 29 & 25 & 4 \\
\hline
\end{tabular}



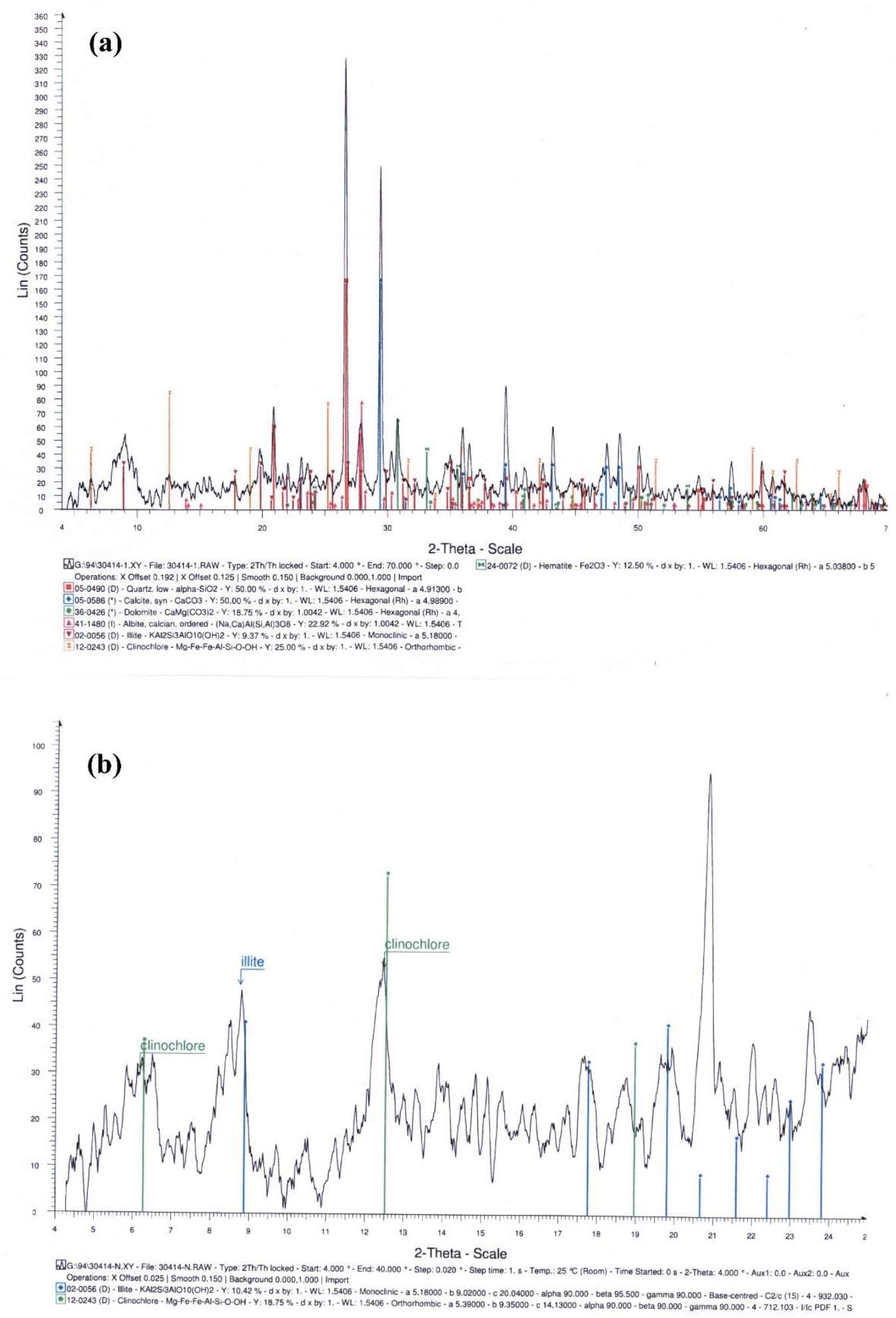

Fig.1. X-ray diffraction plots (a) minerals (b) clay mineral of soil 


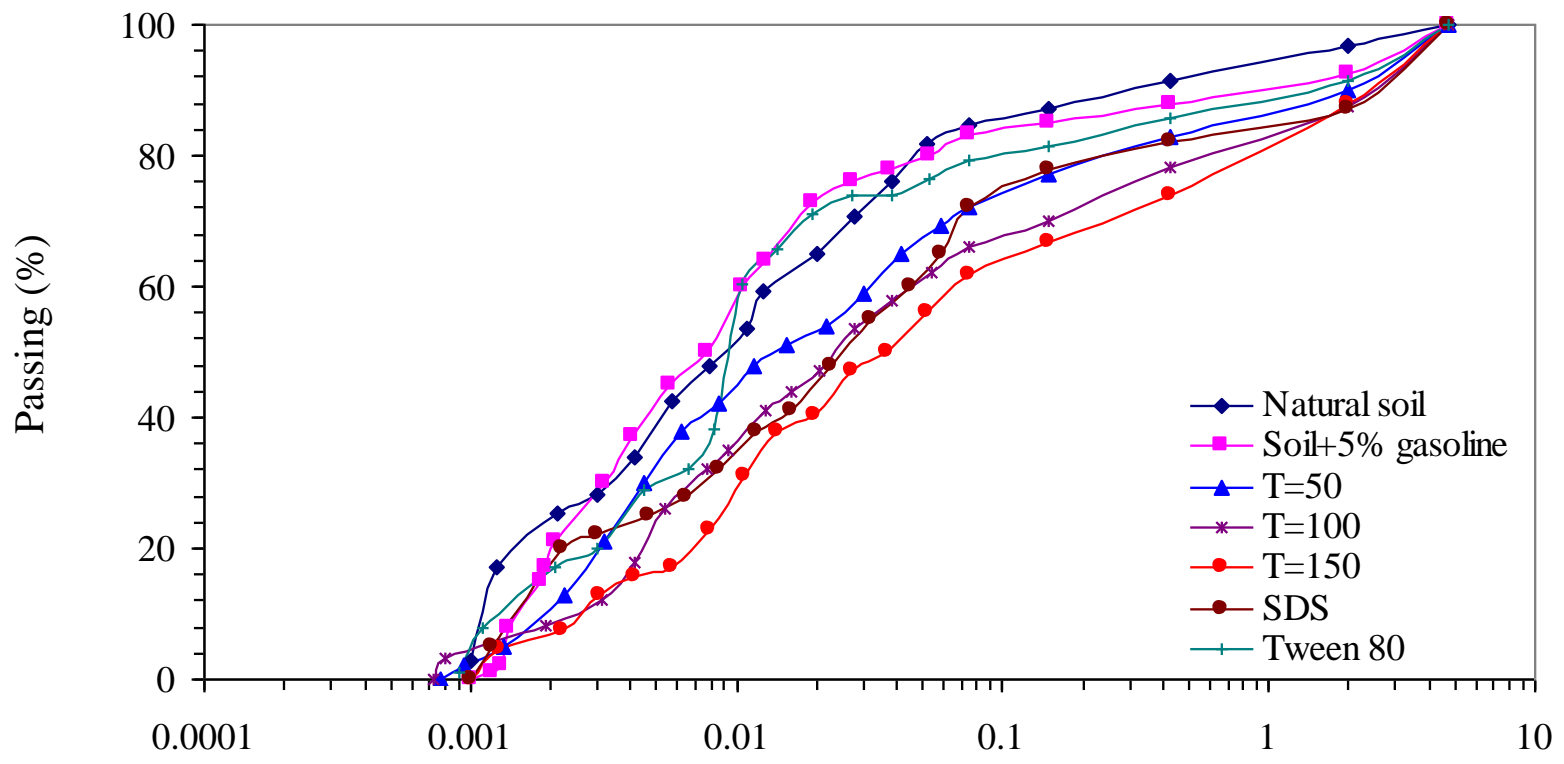

Diameter (mm)

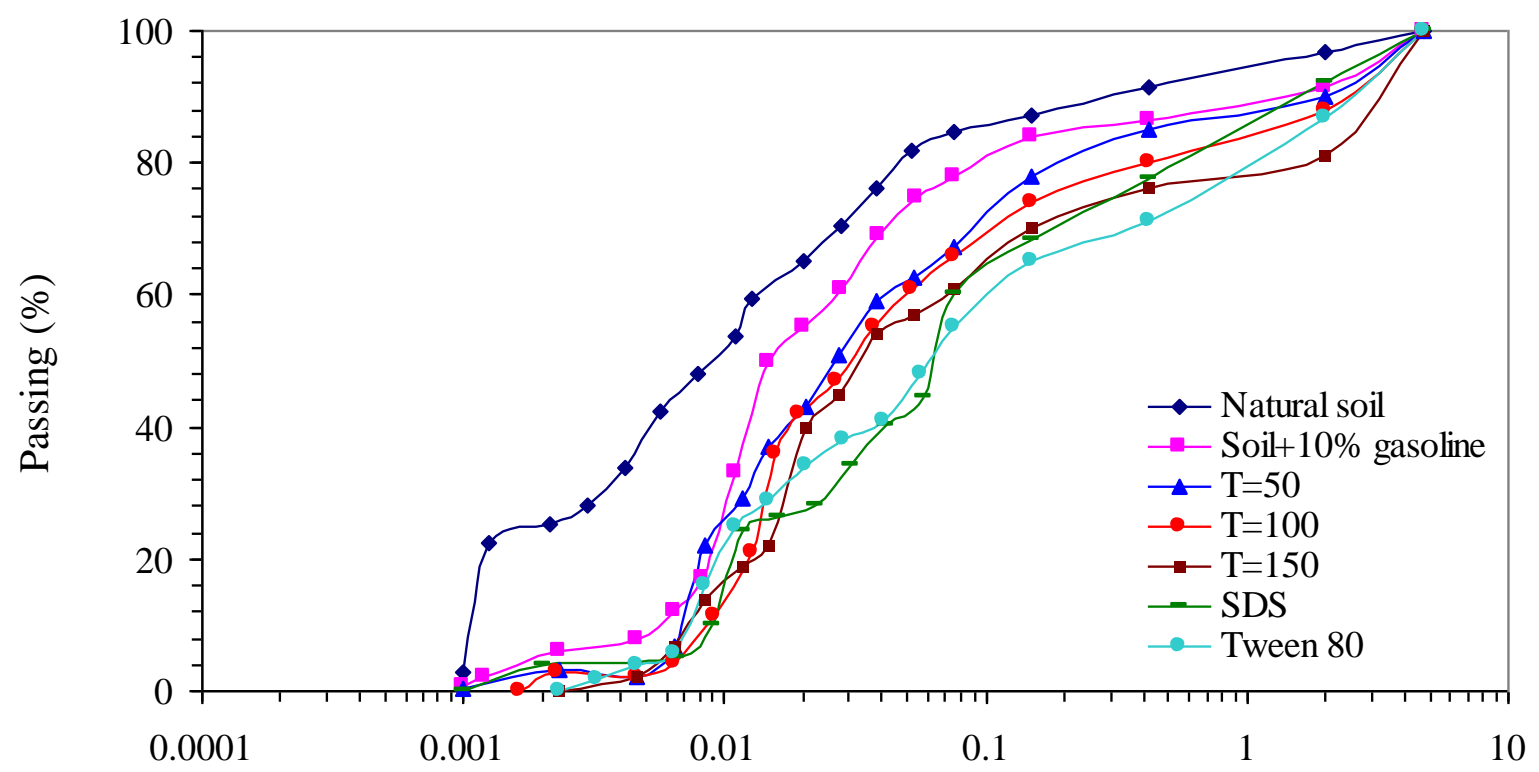

Diameter (mm)

(v) 


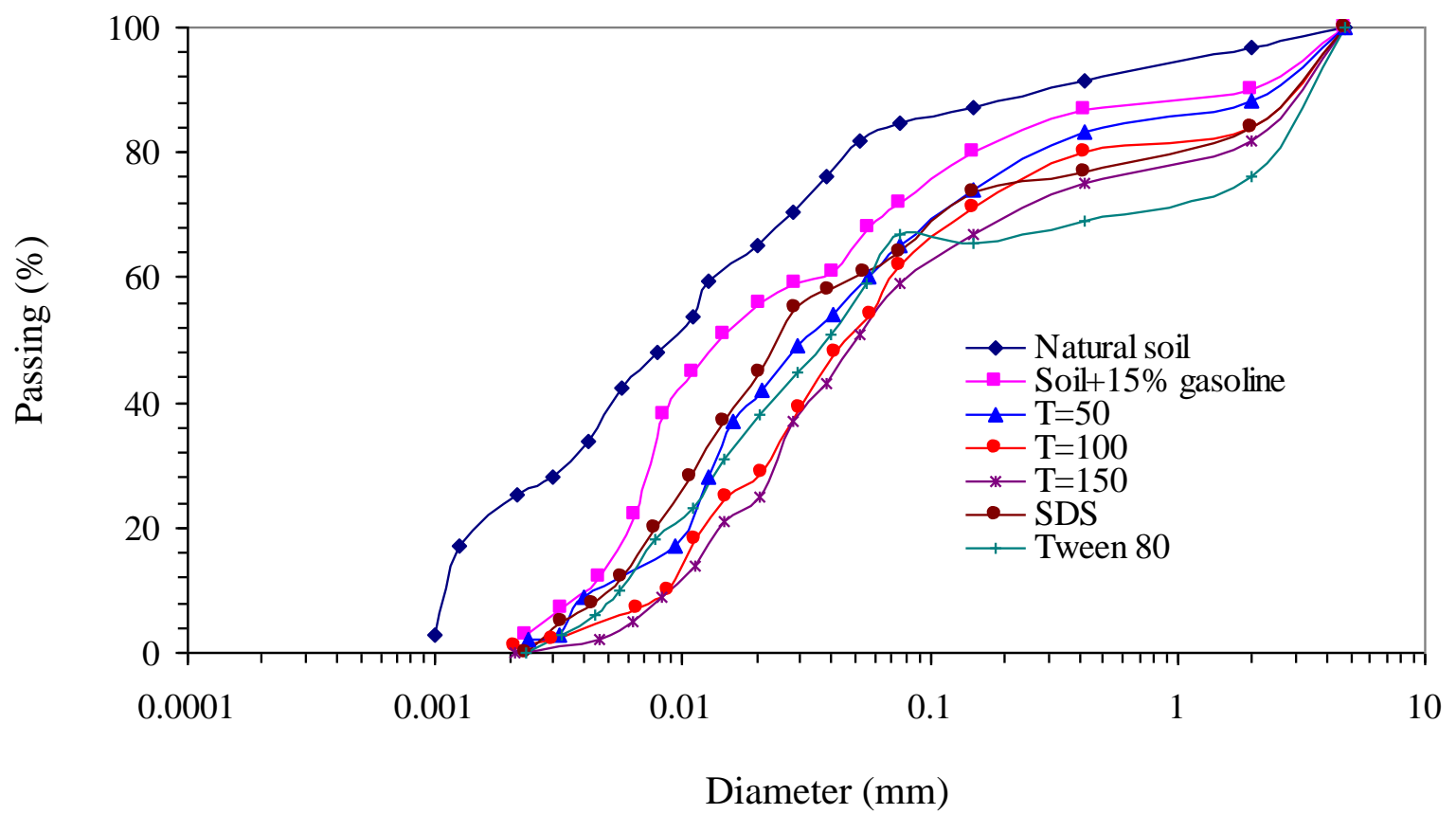

Fig.2. Grain size distribution curves for natural soil, contaminated soil and remediation soil, (a) contaminated with 5\% gasoline, (b) contaminated with 10\% gasoline, (c) contaminated with $15 \%$ gasoline 


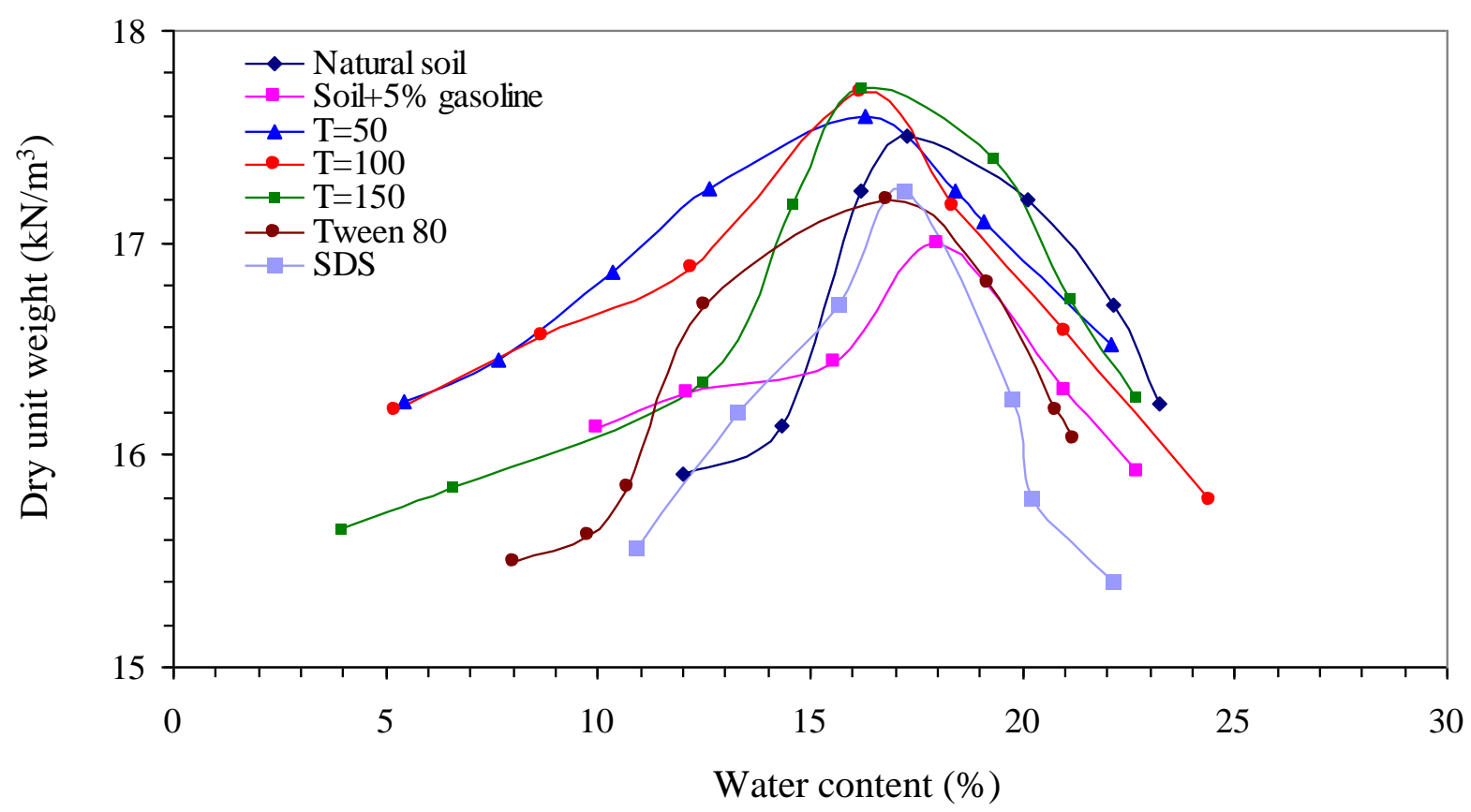

(a)

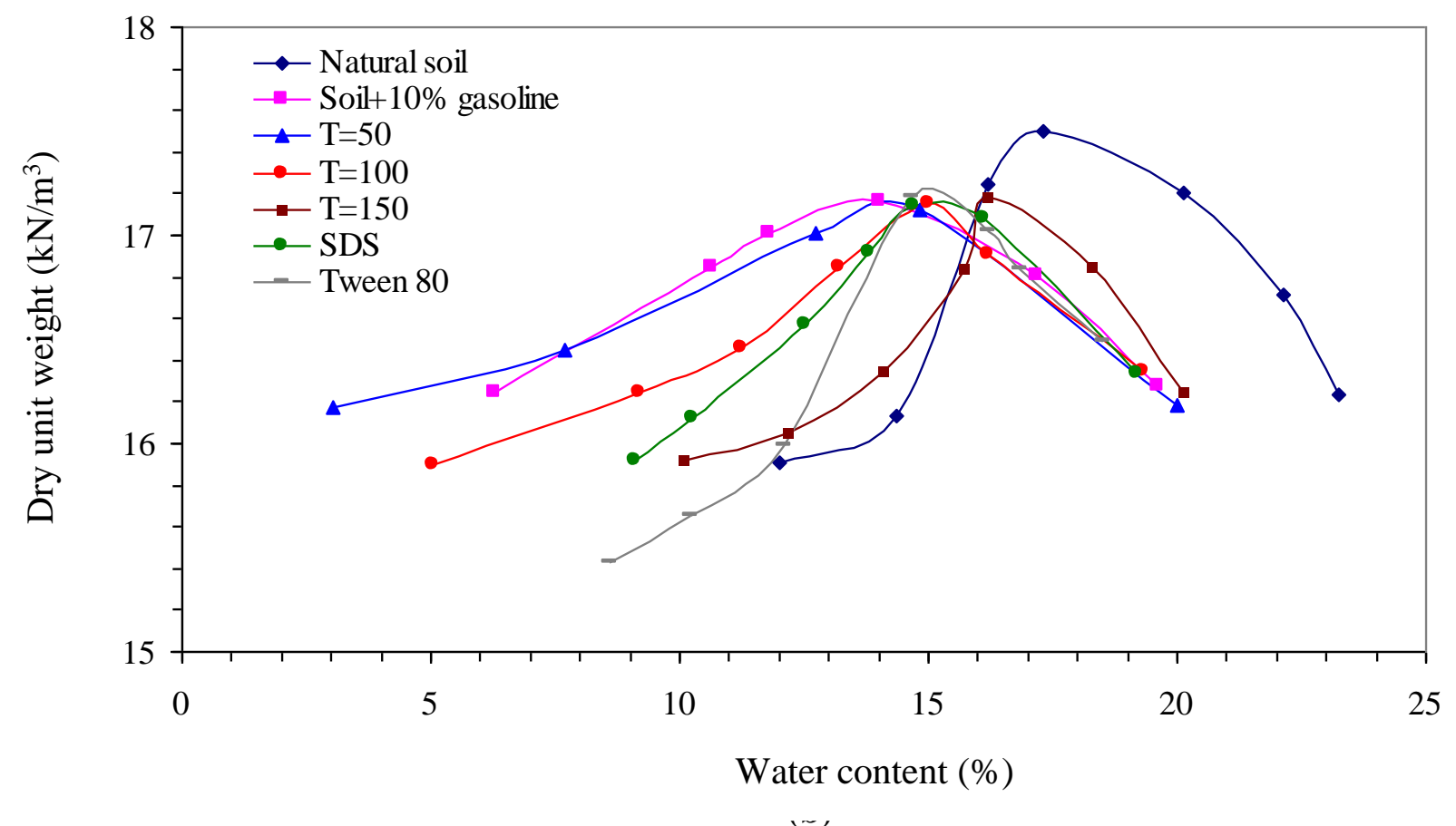




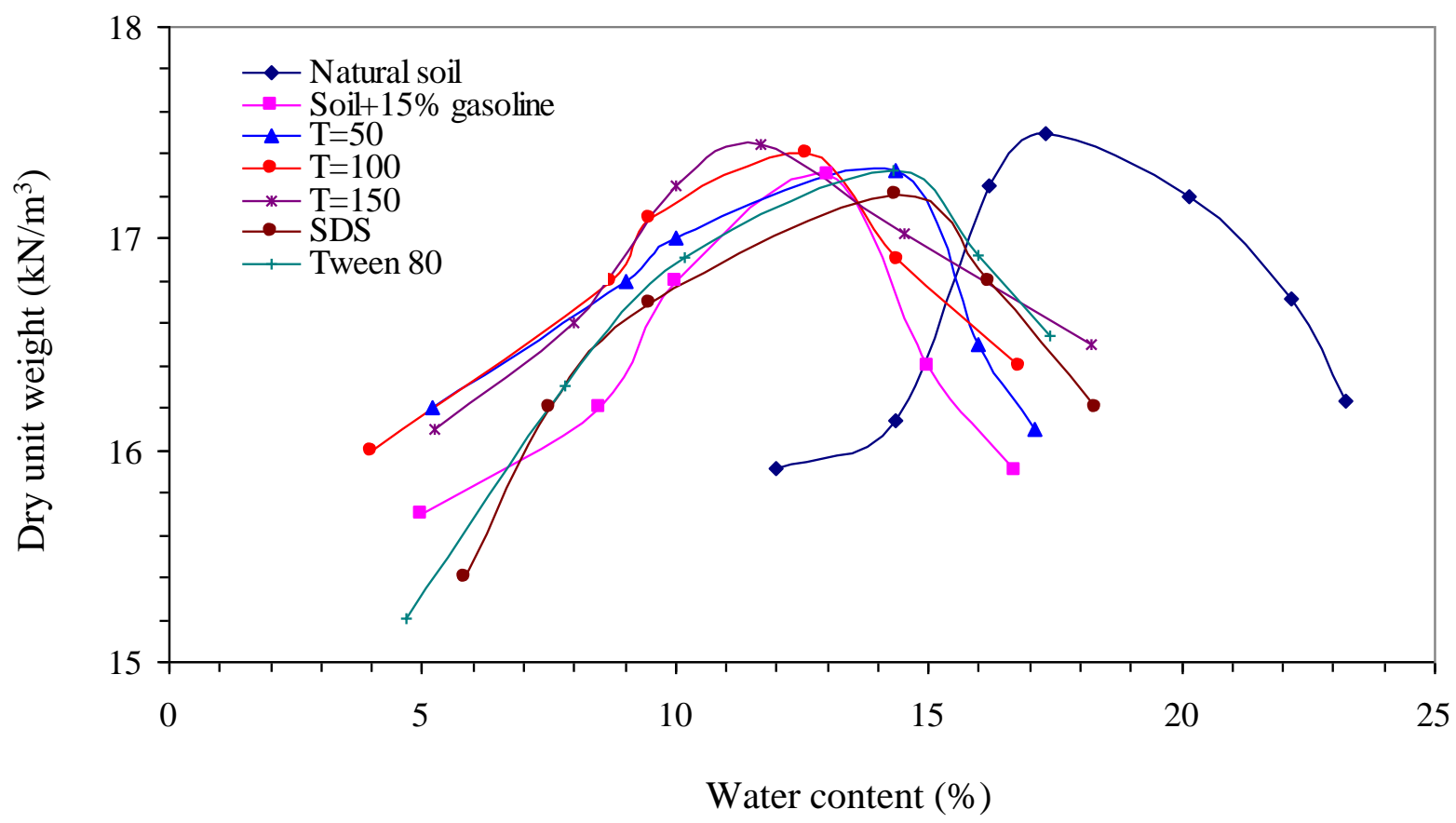

Fig.3. Compaction curves for natural soil, contaminated and remediation soil (a) contaminated with 5\% gasoline, (b) contaminated with 10\% gasoline, (c ) contaminated with $15 \%$ gasoline 


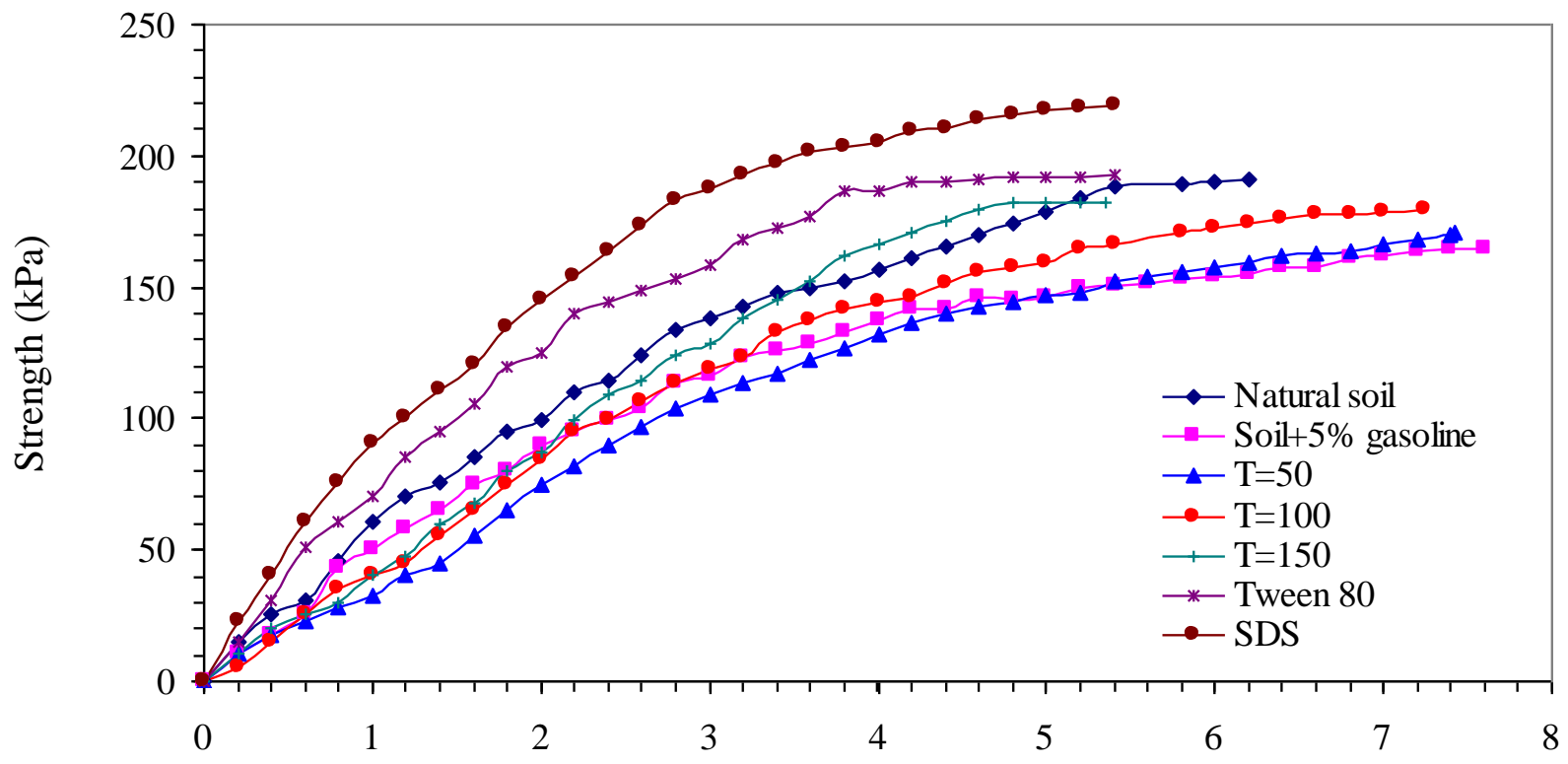

Strain (\%)

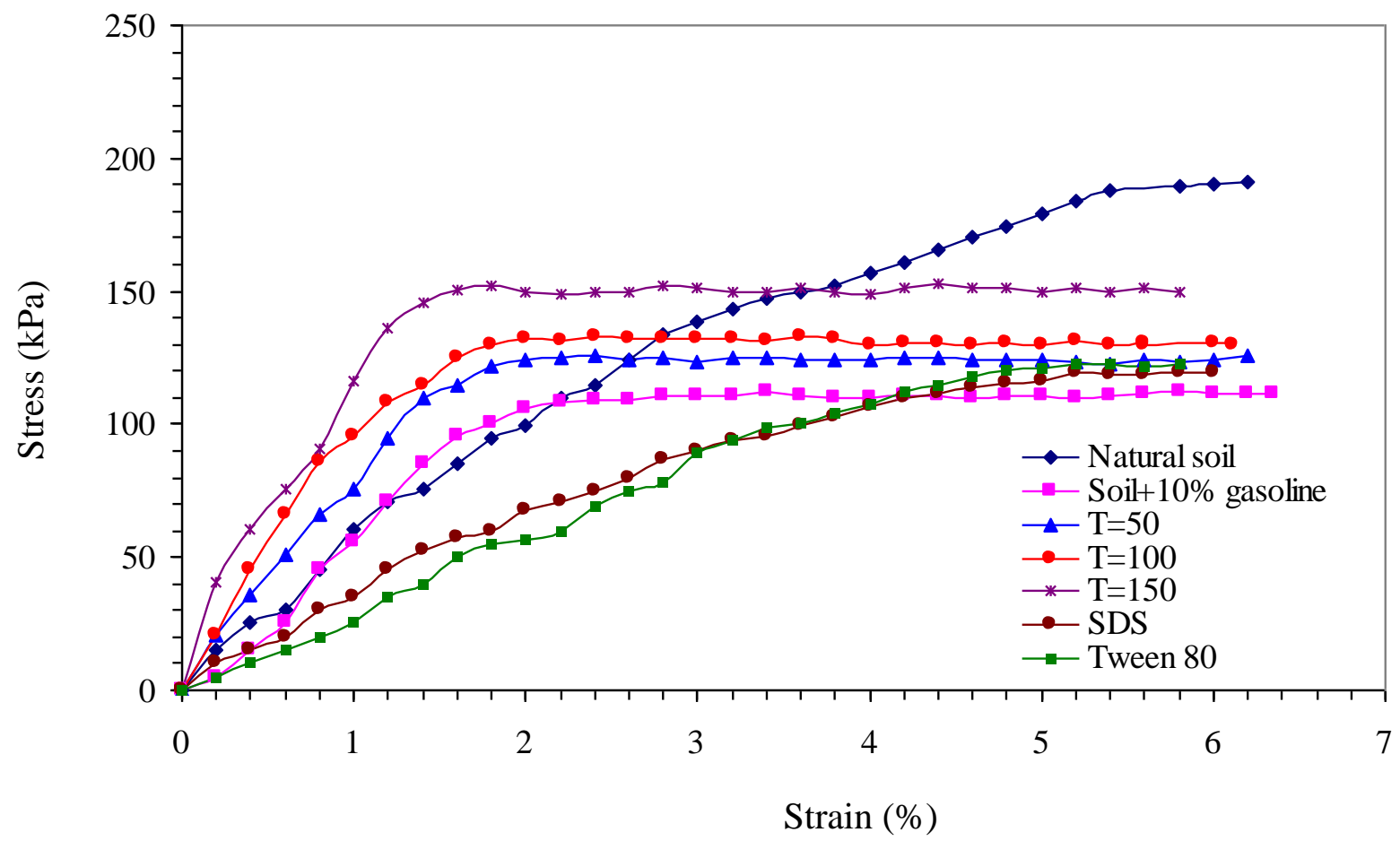

(U) 


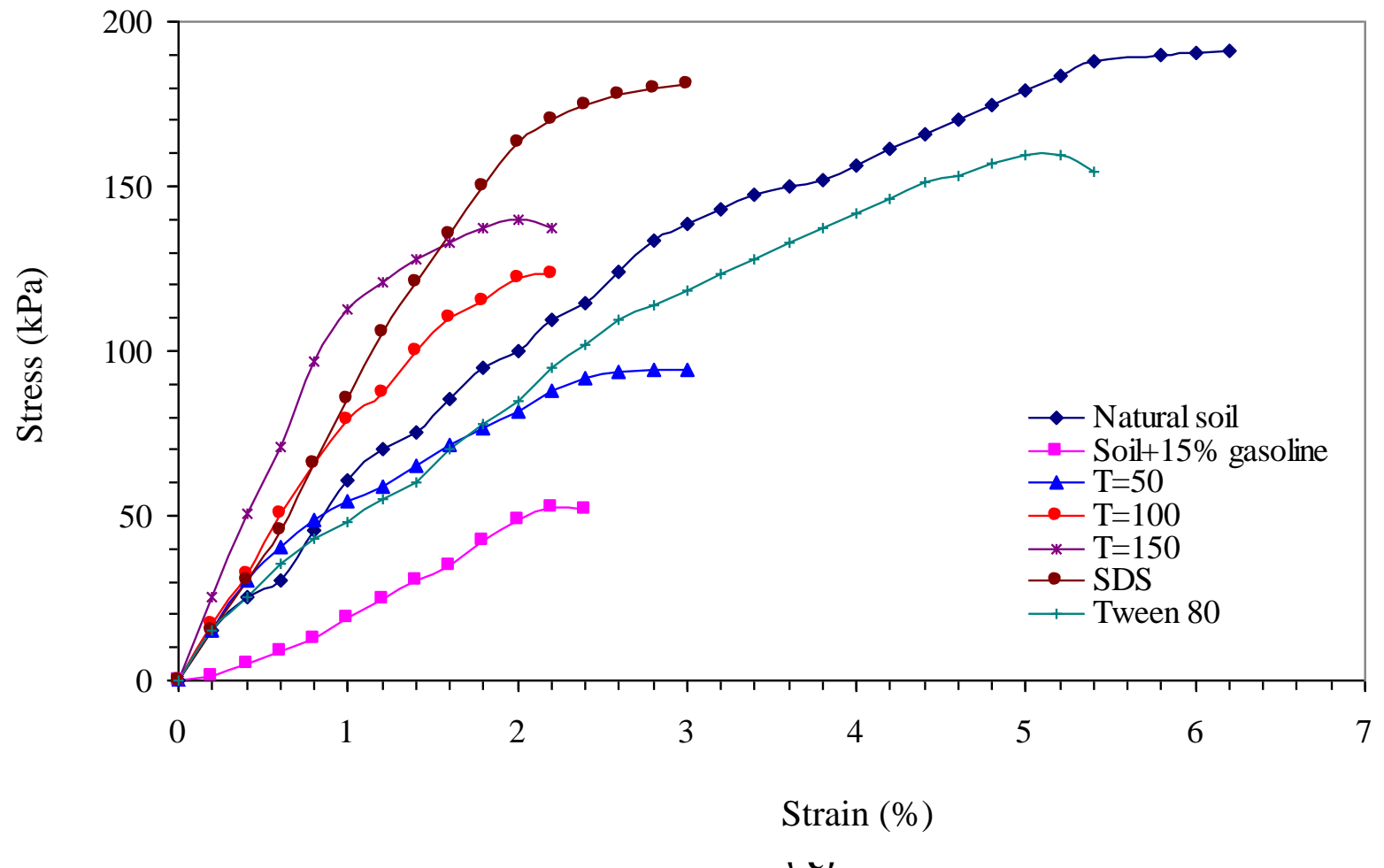

Fig.4. Stress-strain for natural soil, contaminated and remediated soil (a) contaminated with 5\% gasoline, (b) contaminated with $10 \%$ gasoline, (c ) contaminated with $15 \%$ gasoline 


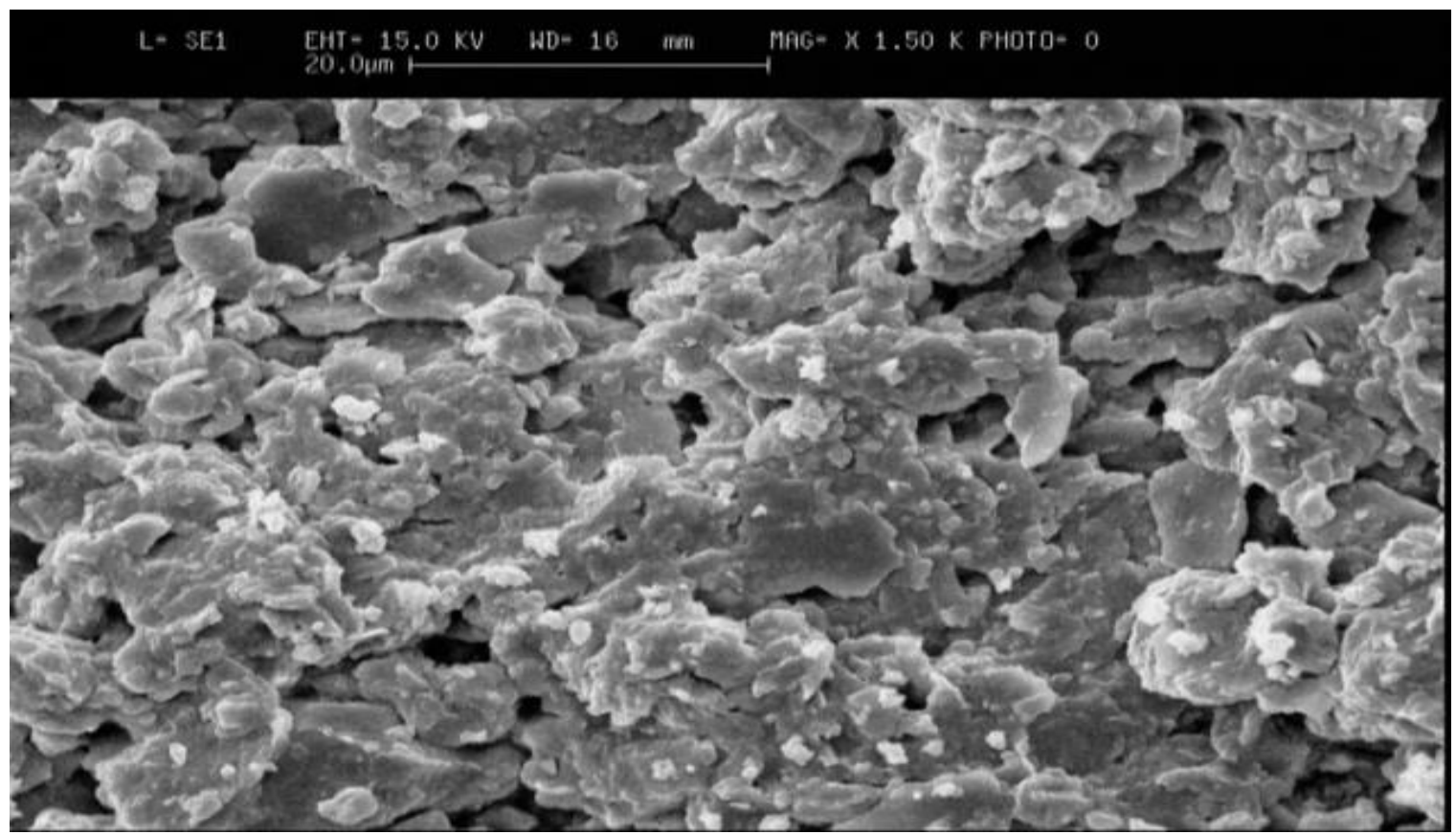

(a)

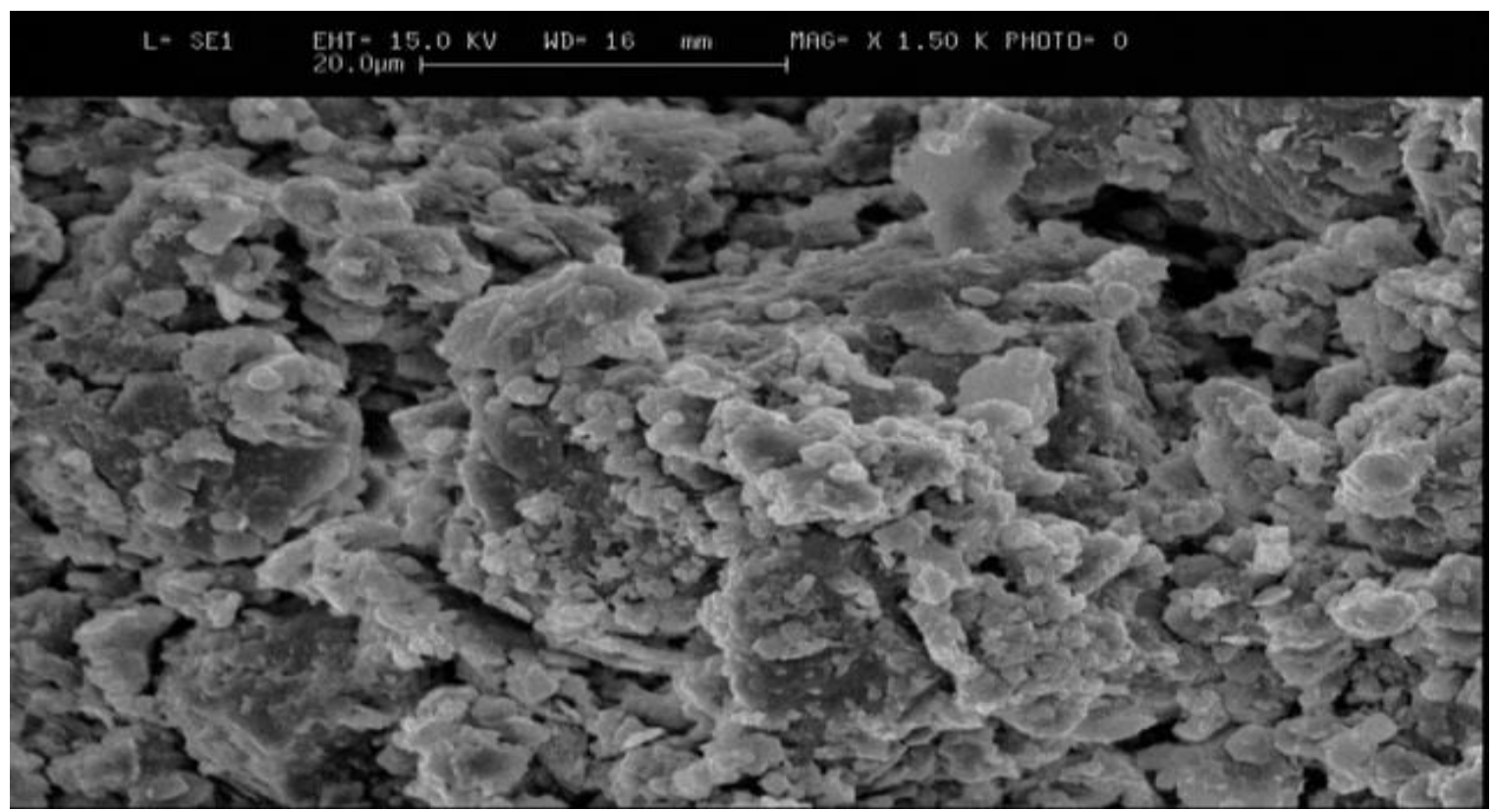

(b)

Fig.5. Scanning electron micrograph of (a) natural soil; (b) soil contaminated with $10 \%$ gasoline 